This is the author's final, peer-reviewed manuscript as accepted for publication. The publisher-formatted version may be available through the publisher's web site or your institution's library.

\title{
Correlates of functional capacity among centenarians
}

Peter Martin, Maurice MacDonald, Jennifer Margrett, Ilene C. Siegler, Leonard W. Poon

\section{How to cite this manuscript}

If you make reference to this version of the manuscript, use the following information:

Martin, P., MacDonald, M., Margrett, J., Siegler, I. C., \& Poon, L. W. (2013). Correlates of functional capacity among centenarians. Retrieved from http://krex.ksu.edu

\section{Published Version Information}

Citation: Martin, P., MacDonald, M., Margrett, J., Siegler, I., \& Poon, L. W. (2013). Correlates of functional capacity among centenarians. Journal of Applied Gerontology, 32(3), 324-346.

Copyright: @ The Author(s) 2011

Digital Object Identifier (DOI): doi:10.1177/0733464811420563

Publisher's Link: http://jag.sagepub.com/content/32/3/324

This item was retrieved from the K-State Research Exchange (K-REx), the institutional repository of Kansas State University. K-REx is available at http://krex.ksu.edu 
Running head: CORRELATES OF FUNCTIONAL CAPACITY

Correlates of Functional Capacity Among Centenarians

\author{
Peter Martin, Maurice MacDonald, Jennifer Margrett \\ Iowa State University \\ Ilene C. Siegler \\ Duke University \\ Leonard W. Poon \\ University of Georgia \\ for the Georgia Centenarian Study ${ }^{1}$
}

${ }^{1}$ Additional authors include S. M. Jazwinski, R. C. Green, M. Gearing, W. R. Markesbery, J. L. Woodard, M. A. Johnson, J. S. Tenover, W. L. Rodgers, D. B. Hausman, C. Rott, Adam Davey, and J. Arnold. 


\begin{abstract}
This study investigated correlates of functional capacity among participants of the Georgia Centenarian Study. Six domains (demographics and health, positive and negative affect, personality, social and economic support, life events and coping, distal influences) were related to functional capacity for 234 centenarians and near centenarians (i.e., 98 years and older). Data were provided by proxy informants. Domain-specific multiple regression analyses suggested that younger centenarians, those living in the community and rated to be in better health were more likely to have higher functional capacity scores. Higher scores in positive affect, conscientiousness, social provisions, religious coping, and engaged life style were also associated with higher levels of functional capacity. The results suggest that functional capacity levels continue to be associated with age after 100 years of life and that positive affect levels and past life-style activities as reported by proxies are salient factors of adaptation in very late life.
\end{abstract}

Keywords: centenarians, functional capacity, psychosocial resources 


\section{Correlates of Functional Capacity Among Centenarians}

Centenarians have the reputation of local celebrities who gain much attention and admiration of family members, neighbors, and service providers. Some of these extraordinary survivors clearly continue to do very well, whereas others have declined - sometimes dramatically - in health and functioning. As more and more older adults achieve very old age, it is important to pay attention not only to the demographic changes but also to aspects of quality of life. One obvious life quality issue concerns physical and functional capacity. The primary purpose of this paper, therefore, was to describe the subjective and functional health among centenarians and to assess potential correlates associated with high or low levels of physical functioning.

The assessment of physical health and functioning has received considerable attention in the centenarian literature. Jeune and Andersen-Ranberg (2000), for example, noted that centenarians show high prevalence rates of morbidity and comorbidity letting them conclude that only a small percentage of centenarian life is autonomous, even though they expect this percentage to increase in the future. Takayama et al. (2007) reported that about one-third of centenarians were physically totally dependent, and a quarter of the centenarians in this study were functioning independently (also see Gondo \& Hirose, 2006; Gondo et al., 2006). Findings from a Swedish centenarian study suggest that about half of their participants managed activities of daily living with or without minor assistance (Samuelsson et al., 1997). The health status assessment of veterans in the United States also indicated that centenarians had significantly worse physical functioning when compared to younger elderly veterans (Selim et al., 2005).

Notwithstanding the evidence of physical and functional limitation for centenarians on average, some centenarians are physically and functionally better off than others, and there is 
surprisingly little research on what predicts these differences among centenarians. The current study extends previous research by relating a number of important centenarian characteristics and behaviors to functional capacity. It is important to examine which variables are related to functional capacity because this might indicate how to improve quality of life when reaching very old age.

A conceptual framework explaining functioning is largely missing in the centenarian literature. The Georgia adaptation model introduced by Poon et al. (1992) is one of the few exceptions providing a guiding framework for adaptation in very old age. Briefly, the Georgia model suggests that environmental support, individual (e.g., personality) characteristics and life experiences and coping behaviors are associated with adaptation in very late life. This model was complemented with Martin and Martin's (2002) developmental adaptation model which adds salient distal components as important variables to explain different levels of adaptation. Our general framework is consistent with life-span and life course perspectives (e.g., Elder \& Shanahan, 2006) as well as resource theories (Hobfoll, 1989) that suggest adaptation in very late life is determined by life-long influences and by the amount of individual and social resources available in very late life.

The purpose of this study was not to test the comprehensive Georgia adaptation model; instead, we use the model to focus on a number of adaption variables that might be associated with functional capacity in very late life. We propose the following domains are associated with functional capacity in very late life: demographic and health factors, positive and negative affect, personality traits, life events and coping, social and economic support, and distal ("life long") influences. 
The first domain was concerned with basic individual characteristics that may explain differences in functional capacity: age (after centenarian status), gender, ethnicity, living conditions (e.g., community or institutional residence), and general health. For a sample 85 years of age and older, increasing age has been reported to be a significant predictor of disability and functional capacity (Hogan, Ebly, \& Fung, 1999), but it is not clear whether this prediction still holds for centenarians. ADL ability was a significant predictor of continued survival after 100 (Poon, Johnson, Davey, Dawson, Siegler, \& Martin, 2000). There are inconsistent findings about gender as a predictor of functional capacity. Liang et al. (2003) reported for a Japanese sample that men were more likely to be functionally impaired than women. Fiksenbaum, Greenglass, Marques, and Eaton (2005), on the other hand, noted that men in their study of older adults had higher functional capacity scores than women. With regard to ethnicity, studies have pointed out racial disparities in disabilities with African Americans reporting higher disability levels than Whites (e.g., Mendes de Leon, Barnes, Bienias, Skarupski, \& Evans, 2005). Finally, several studies have pointed out that self ratings of health were associated with changes in functional capacity (Anderson, James, Miller, Worley, \& Longino, 1998; Atchley \& Scala, 1998; Idler \& Kasl, 1995).

The second research question evaluated the question to what extent positive and negative affect may be associated with relative functioning in very old age. Only few studies have investigated the association between mental health and functional capacity. For example, Parmelee, Lawton, and Katz (1998) reported that depression predicted functional disability and decline in functional capacity.

The third association evaluated in our study concerned individual ("personality") resources that may explain functional differences among centenarians. Surprisingly little 
research has linked personality with functional capacity. Duberstein, Sörensen, and Luness (2006) noted that openness to experience was positively associated with functional capacity. Krueger, Wilson, Shah, Tang, and Bennett (2006) reported that extraversion and conscientiousness decreased the risk of becoming disabled in a sample of Catholic nuns.

The fourth area was concerned with social and economic resources responsible for individual differences in subjective and functional capacity. Lower levels of income and wealth have been associated with higher mortality risk (e.g., Feinglass et al., 2007). Satisfaction with social support has also been associated with functional capacity (Fiksenbaum et al., 2005). Avlund, Lund, Holstein, Due, Sakari-Rantola, and Heikkinen (2004) also noted that social contact was positively related to functional capacity.

The fifth question investigated life events and coping influences on functional capacity. One study reported that mastery was as a predictor of functional capacity in oldest-old populations (Femia, Zarit, \& Johansson, 1997). Specifically, religious coping may be important for centenarians (Martin, Rott, Poon, Courtenay, \& Lehr, 2001), providing a source of strength that may boost one's own perceptions about functional capacity.

The final assessment concerned "distal" influences that may be responsible for differences in late life functioning. In recent years, more attention has been paid to life course course epidemiology (Ferraro, 2006) incorporating elements of early life in the study of healthy aging. One of the most obvious distal influences is the lifelong influence of education. Education has been linked to functional capacity (Liang et al., 2003) and physical health (Clark, Stump, Miller, \& Long, 2007). Adverse childhood experiences have also been studied as influences of the past. For example, adults who reported abuse as a child or who lived in a dysfunctional family had worse health assessments when compared to adults who did not experience these 
traumatic events (Felitti et al., 1998). Krause, Shaw and Cairney (2004) reported that stressful events in young adulthood or midlife were more consequential for health in later life than recent events. It is not clear whether these distal variables have an effect on functional capacity in late life. Taken together, these studies support a "long view of aging," emphasizing cumulative disadvantages over the life course (Ferraro, 2006).

Because centenarians often have sensory and cognitive limitations, data collection of this special age group has often relied on proxy reporters including family members or service providers (Gu, 2008). Proxy-self report comparisons have a long history in health surveys (e.g., Mosley \& Wolinsky, 1986), symptom reporting (e.g., Clarridge \& Massagli, 1989), and reports of disability (e.g., Todorov \& Kirchner, 2000).

Information from proxy informants can be very useful (Watkins, Guariglia, Kaye, \& Janowsky, 2001). For example, Loewenstein et al. (2001) reported that close family informants were particularly valuable, because cognitively impaired and demented adults may be inaccurate in the assessment of their own functional abilities with a tendency to underestimate deficits. Rodgers and Herzog (1992) noted a general consensus among researchers that proxy respondents should be used in research focusing on oldest-old adults to avoid biasing the data compared to healthy elderly. This suggestion was echoed by investigators of other centenarian studies. Gu (2008), for example, argued that more proxies should provide information in place of centenarians.

The literature, however, is not unequivocal concerning the accuracy of proxy informants (Neumann, Araki, \& Gutterman, 2000). For example, Kolanowski, Hoffman, and Hofer (2007) reported that the concordance of self-report and informant assessments of emotional well-being among nursing home residents was low. MacDonald, Martin, Margrett, and Poon (2009), on the 
other hand, showed there was no mean difference in centenarians' mental health ratings when compared to proxy reports.

Evidence suggests that under certain circumstances proxies are reliable as a source of information. For example, elder-proxy concordance is typically high for such items as activities of daily living, medical history, and instrumental activities of daily living (Schatzberg, Sudha, \& Mutran, 1998). Data from personality assessments suggest that even though there are mean differences on some personality trait ratings, these differences are only in degree and not in substance (Martin, 2007). Neumann et al. (2000) conducted a Medline review of 24 clinical studies that used proxy data and concluded that proxy- and subject reports are often comparable in describing level of functioning, overall health, chronic physical conditions, and physical symptoms. Schneider and Schimmack (2009) reported that self-informant agreement in wellbeing ratings was influenced by construct, age of the target participant, and number of items in the measure. Higher agreement in this meta-analysis was more likely to be obtained for positive than for negative traits, for older rather than younger age, and for multiple- rather than singleitem measures. Han, Burns, Weed, Hatchett, and Kurokowa (2009) tested the measurement equivalence of self-reports and peer ratings for a coping inventory and reported that self-rating data fit the theoretical model better, whereas peer ratings showed higher reliability.

Collectively considered, results from these studies indicate that the use of proxies to obtain data across selected domains is important (Walsh, Wu, Mitchell, \& Berkmann, 2003). However, as others have cautioned, proxy scores cannot simply be used as substitutes (Kane et al., 2005) but should instead be viewed as additional (“supplemental”) information.

In this study, proxies provided information about the centenarians. Some of these proxy assessments are easier to do because informants rate specific tasks (i.e., ADL assessments), 
whereas other assessments are clearly more difficult to obtain (e.g., positive affect) because they are less observable. However, as the literature reviewed indicates, informant data can be a valid source and may make a contribution to better understand factors influencing functional capacity in very old age. As a number of centenarians are unable to answer questions reliably about themselves, using informant data may be the only source of reliable information.

The primary research question for this study was whether demographic and health characteristics, positive and negative affect, personality, social and environmental support, life events and coping, as well as distal influences indicate whether the oldest individuals in our society report relatively high or low scores on functional capacity. We expected that older age, worse subjective health, Neuroticism, low levels of social and economic support, more stressors, poorer coping behaviors and poor education and distal life events were associated with poorer functional capacity.

\section{Method}

\section{Participants}

The study included 234 community-dwelling and institutionalized centenarians and nearcentenarians from the second Georgia Centenarian Study (Phase III, Poon et al., 2007). Our sampling plan had two components. The first included a census of all skilled nursing facilities (SNF) and personal care homes (PCH) located in a 44-county area of Northern Georgia and the identification of all residents of a sample of those facilities who were age 98 and older. The second component relied on lists of registered voters, again across the entire 44-county area, and using the date-of-birth information contained on those lists to identify individuals who were age 98 and older. 
Lists were generated of SNFs and PCHs in each of the 44 counties, and interviewers called each of the selected facilities, explained the study, and requested the names of all centenarians and near-centenarians currently residing in that facility (Poon et al., 2007). We also listed all centenarians and near-centenarians (that is, all individuals who had their $98^{\text {th }}$ birthday on or before the date of the start of data collection in a given stratum), who were on the voter registration lists and for whom their address indicated that they resided in one of the counties in that stratum. No exclusion criteria were used other than age and residence in the 44 counties. Participants on the list were contacted and explained the purpose of the study. Participants then provided informed consent before the interviews started.

Because of the complex sampling and recruitment methodology used in this study, it is not possible to estimate a refusal rate for this study. Doing so requires the ability to first determine eligibility and to establish contact with all eligible individuals. However, our best estimates suggest that the population of eligible centenarians for this study was 1244 . Thus, our sample reflects participation of fully $19.2 \%$ of the entire population. One hundred thirty five refusers provided information to suggest that they were age-eligible for participation (yielding an effective response rate of at least $63.9 \%$ ), a fraction of whom also provided additional demographic information, in whole or in part. Examination of this additional indicated that nonresponders had very similar characteristics in terms of age $(M=99.8$ years, Range $98-106)$, gender (84.4\% women), and race $(75.6 \%$ white $)$.

As would be expected, the majority of the participants $(82.5 \%)$ were women and White (76.5\%). In terms of marital status, the majority (86.3\%) was widowed, $4.7 \%$ were married, and $4.3 \%$ were divorced. A sizeable group (59.7\%) had no more than a high school education, whereas $17.9 \%$ had a college degree. Almost half of the centenarians resided in their private 
home or apartment (44.2\%), whereas $20.2 \%$ resided in assisted living facilities and $35.6 \%$ in nursing facilities. Most centenarians (72.9\%) reported that their health was either good or excellent. The average MMSE score (Folstein, Folstein, \& McHugh, 1975) of the participants was $M=17.12$. Demographic data are summarized in Table 1 .

The data used in this study were collected from proxy informants. Proxies were instructed not to talk with the centenarians and to provide their own perspective.

Proxy informants were selected in the following fashion: first close family, such as spouses or children were considered as proxies. If more than one child was alive, the centenarian nominated a proxy, or in the case of cognitive impairment, a contacted child made the decision about who could provide the most accurate information. Other relatives served as proxies if no children were alive or available or if so nominated by the participant. If no other relatives were alive or available, friends, neighbors, nurses, clergy or other knowledgeable person also served as proxies. Most proxies (61.1\%) were adult children. Additional proxies included nieces and nephews (13.9\%), granddaughters (9.9\%), and miscellaneous informants, such as spouses, siblings, or friends (15.1\%). Eight proxies did not returned the mail-back questionnaire and additional eight proxies were excluded because their own mental status scores were too low (MMSE <23), resulting in a proxy sample size of 234 participants. Proxy scores about centenarians were obtained for all variables in the study.

Data collection of centenarians was performed by the data acquisition team of the Georgia Centenarian Study. The MMSE data were collected in the core assessment by trained interviewers. Proxy informants filled out a questionnaire and mailed the questionnaire back to the interviewer.

\section{Measures}


Basic demographic and health predictors. Age, gender, ethnicity were assessed as demographic variables. Residence was assessed in three different groups: community-dwelling, personal care homes, and skilled nursing facilities. A general health rating was provided by proxies who evaluated the overall health from the Duke Older Americans Resources and Services Procedures (OARS, Fillenbaum, 1988): "How would you rate your overall health at the present time — excellent, good, fair, or poor?” A high score indicated better perceived health.

Individual resources. For the assessment of individual resources, the NEO-PI R (Costa $\&$ McCrae, 1994) was used and once again assessed by proxies. Proxies were instructed to respond as they viewed the centenarian "today, not how it might have been in the past." Items were phrased with regard to the centenarian (e.g., "She/he is not a worrier" or "she/he really likes most people she/he meets"). The NEO contains the five traits Extraversion, Neuroticism, Openness to Experience, Agreeableness, and Conscientiousness. Missing data replacements for the NEO were computed individually (i.e., case-by-case item deletion) following a procedure described by Schafer and Graham (2002) for those proxies who answered at least one question for each of the traits. If missing data occurred on a personality trait, the total score of all answered questions by a particular person was divided by the number of response items of that person and multiplied with the number of items for each trait. For proxies, Cronbach's alphas for Neuroticism, Extraversion, Openness to Experience, Agreeableness, and Conscientiousness were $\alpha=0.93, \alpha=0.90, \alpha=.86, \alpha=.94$, and $\alpha=.95$, respectively.

Social resources. Proxies rated social provisions with the Social Provisions Scale consisting of 12 items of which six were positively worded (e.g., "There are people s/he can depend on to help him/her, if s/he really needs it"), and six were worded negatively (e.g., "There is no one s/he can turn to for guidance"). A summary score was calculated by recoding all the 
negatively worded items to obtain a positive summary score for the scale (Cutrona \& Russell, 1987). Cronbach's alpha for the Social Provisions Scale was $\alpha=0.70$ for proxies. Higher scores indicated greater perceived social support.

Perceived economic status. Perceived economic status was assessed with the economic resources scales from the OARS (Fillenbaum, 1988). These questions probe perceptions participants have about their economic resources (e.g., "Are your assets and financial resources sufficient to meet emergencies?" or "How well does the amount of money you have take care of your needs?"). The three items yielded a reliability of $\alpha=0.81$ for proxies. Higher scores indicate increased perceptions of economic status sufficiency.

Affect. Positive and negative affect was assessed by the proxies who filled out the Bradburn Affect Balance Scale (Bradburn, 1969). The scale consists of the two dimensions "positive affect" and "negative affect." Each scale consists of five items with the categories "not at all," "once," "several times," and "often." For proxies, internal consistency was $\alpha=.79$ for positive affect and $\alpha=.74$ for negative affect. Higher scores for positive affect indicated better mental health, whereas higher scores for negative affect were indicative of poorer mental health.

Although it may be difficult to assess some of the items and dimensions of affect balance by proxy, it is still important to take into account the observations by proxies. Proxy informants typically can observe whether centenarians are "depressed and very unhappy," "restless," "bored," or "lonely." Of course, these observations may not match those that would be obtained by self ratings.

Coping. Coping skills were assessed with two items measuring religious coping. These items were used in our previous studies with centenarians and were ranked as the most often used coping behaviors. The two items were, "I pray for guidance and strength" and "I rely on my 
religious beliefs." Cronbach's alpha for religious coping was $\alpha=0.72$. Higher scores indicated more religious coping.

Lifestyle. Past engaged lifestyle activities were defined by a series of cognitive engagement tasks participants may have engaged in at any time of their lives (Hultsch, Hertzog, Small, \& Dixon, 1999). These past engaged lifestyle activities included eight dichotomous questions such as learning a foreign language, volunteerism, working, traveling, preparing income tax, and public speaking. Cronbach's alpha was .62 for proxies. Higher scores were indicative of greater engagement.

Events and experiences. Proximal and distal life events were selected from a commonly used life events list (e.g., Dohrenwend, Krasnoff, Askenasy, \& Dohrenwend, 1978). These events refer to occurrences such as death of a parent, separation or divorce of parents, marriage, divorce, death of close family members, the events of children (births or loss), job events (first job, change of jobs, and retirement), a major financial loss, a residential change including institutionalization, a major decrease in activities that one really enjoyed, or worsening relationship with a child. We assessed a total of 23 events and their time of occurrence; events were then classified as to whether they had happened two or fewer years ago ("proximal events"), and whether these events had happened more than 20 years ago ("distal experiences"). These events were summed to obtain a cumulative event score. Consistent with the notion of cumulative advantage and adversity (Ryff, Singer, Love, \& Essex, 1998) we assessed the effect of these cumulative events rather than discrete events or negative vs. positive events.

Education and occupation were measured with the OARS assessment (Fillenbaum, 1988), dividing education into eight categories ranging from $0-4$ years $(=1)$ to postgraduate education (=8). Occupation was coded in ten categories from "farm laborer" to "professional." 
Functional capacity. Functional capacity was assessed with the Self-care Capacity Scales from the OARS (Fillenbaum, 1988). The 14 items assess the difficulty participants have with instrumental tasks (e.g., shopping, cooking, and cleaning) and physical tasks (e.g., bathing or showering, dressing, eating, getting in and out of bed or a chair, walking, getting outside, and using the toilet). Proxies responded whether centenarians had " $2=$ no problems," needed “ $1=$ some help," or were " $0=$ completely unable" to do the task. The functional capacity questionnaire of the OARS is highly reliable (Fillenbaum, 1988). In this study, the internal consistency (Cronbach's alpha) was .90 for proxy reports. A higher score indicated better functioning.

\section{Data Analyses}

Data analyses included descriptive data analyses and a series of multiple linear regression analyses. The multiple linear regression analyses were first conducted by domain (i.e., demographic and health variables, positive and negative affect, personality, social and economic resources, coping and life events, and distal influences). A final regression analysis was conducted with a combined set of variables obtained from the domain-specific analyses. SPSS 18 was used for all analyses.

\section{Results}

First, descriptive analyses were computed for the sample (Table 2). Proxy reports on overall health of the centenarians were high, with 79.8 percent indicating that centenarians were in good or excellent health. High scores were obtained for social provisions, perceived economic status, and religious coping. Relatively low scores were obtained for negative affect. 
Six separate multiple regression analyses were computed to examine the hypothesized predictor cluster in accounting for centenarian functional capacity. Domain-specific analyses were computed first. Table 3 summarizes the results. For the demographic and health domain, age, residence, and global health were significantly associated with functional capacity. Older centenarians, those rated to be in worse health and those residing in long-term care facilities had lower functional capacity scores.

For the next five regression models, age, gender, and ethnicity were used as covariates. Turning to the model of positive and negative affect, positive affect was significantly associated with functional capacity: Participants who had higher positive affect scores were reported to have higher scores in functional capacity.

Of the personality model, reported by proxies, Conscientiousness was significantly related to functional capacity. Social resources and perceived economic status were associated with functional capacity, suggesting that centenarians who reportedly had higher social provisions scores and better economic resources had higher functional capacity ratings.

Religious coping was also associated with better functional capacity as were higher scores in engaged lifestyle. Life events (either proximal or distal), and education and occupation were not associated with functional capacity.

A final regression model that included significant domain-specific variables was computed (Table 4). Age, positive affect and engaged life style were significantly associated with functional capacity. Younger centenarians, those with higher scores in positive affect and engaged lifestyle were reported to have higher scores in functional capacity. The final model explained 33 percent of the variance.

\section{Discussion}


The impairment of functional capacity signifies one of the most severe limitations for centenarians affecting the quality of life in critical ways. Therefore, it is important to find correlates of functional capacity that help to explain why some centenarians are perceived to function well, whereas others report significant limitations. Proxy informants are important observers of centenarians who can provide assessments of the centenarians' capacity to take care of themselves.

The proxies generally rated the centenarians in positive ways: proxy-rated health was high, as were social and economic support and religious coping. Proxies rated the centenarians relatively low in negative affect. The evaluations may be explained by expectations proxies have for people at 100 years of age. Family member often view centenarians positively because they are rare survivors and by that definition unique. Furthermore, social support may be biased by the fact that the proxies who rated the social support in many cases were the primary support providers.

In addition to these general assessments, we tested six alternative hypotheses addressing individual differences in functional capacity. Would demographics, affect levels, personality, social and economic resources, life events and coping, and distal influences explain differences in functional capacity? Our results suggest that all domains play an important role.

The strongest correlates of functional capacity were the general health evaluation, age, and residence. Older centenarians, those in poorer health, and those residing in care facilities had lower scores in functional capacity. These results are not surprising because one of the main reasons for older adults to move to a long-term care facility is their deteriorated level of functional capacity (Steinbach, 1992). Other studies have demonstrated that among oldest old adults, increasing age is a significant predictor of disability and functional capacity (Hogan et al., 
1999). Particularly at the end of the biological life-span this appears to be the case and this is supported by studies indicating that functional capacity predicts continued survival after 100 (Poon et al., 2000). With regard to gender and ethnicity, we did not find differences in functional capacity. This stands in contrast to other reported studies linking these demographic characteristics to functional capacity (Fiksenbaum et al., 2005; Liang et al., 2003; Mendes de Leon et al., 2005). Previous studies, however, have been conducted with younger old adults and it is possible that gender and ethnicity differences converge at the very end of the biological lifespan.

Proxy ratings of physical health relate to functional capacity because proxy caregivers may judge the overall health of a centenarian family member by their capacity to fulfill basic tasks. Our results are consistent with other studies that reported a statistical association for subjective health and functional capacity (Anderson et al., 1998; Idler \& Kasl, 1995).

In addition to physical health ratings, the proxy ratings of positive affect (but not negative affect) were associated with functional capacity. Perhaps centenarians with positive emotions also are more likely to continue their engagement in activities of daily living or - in reverse centenarians who are seen to engage in activities of daily living are more likely to be rated with a positive outlook and as showing positive affect.

Of the personality variables, Conscientiousness was significantly related to functional capacity. Centenarians who were rated higher in Conscientiousness also were seen as performing better in daily activities. Several personality traits of the Big-5 have been linked to health and functional capacity in previous research (Duberstein et al., 2003; Krueger et al., 2006). In this study, the only association of functional capacity was with Conscientiousness. This particular trait has been noted in other studies as being related to longevity (Friedman et al., 1995). High 
levels of conscientiousness may be associated with health-relevant activities which then in turn influence better functional capacity (Friedman et al., 1995).

Social and economic ratings by proxies were also significantly associated with better functional capacity. Lower levels of income and wealth have been related to higher mortality risk (Feinglass et al., 2007) but the association between economic resources and functional capacity has not received sufficient attention. Such resources, however, are important when engaging in a number of daily activities. Other studies have also indicated a positive association between social support and functional capacity (Avlund et al., 2004; Fiksenbaum et al., 2005). Perhaps the continued encouragement by a social support system may prompt centenarians to continue their engagement in activities of daily living. Of course, in our study the social provisions ratings might have been biased by the fact that the proxies rated social support and functional capacity. Proximal events ("stressors") in the lives of centenarians does not appear to influence the level of functional capacity. Religious coping, on the other hand, was associated with functional capacity. Religious coping is an important coping behavior for centenarians (Martin et al., 2001) and could be an important source of strength when performing tasks of daily life becomes more difficult.

Of the distal variables, only engaged lifestyle was positively associated with higher levels of functional capacity. Centenarians who had been engaged in a number of life-time activities such as volunteering, traveling, or giving public speeches were more likely to be rated higher in their daily activities of daily living. These results confirm life course perspectives on aging (Elder \& Shanahan, 2006) and the developmental adaptation model (Martin \& Martin, 2002) that highlight the importance of activities over the entire life-span. Even though the other distal variables, such as life events in the past, education and occupation, were not associated with 
functional capacity, there is some evidence suggesting that a "long view of aging" (Ferraro, 2006) ought to be taken when assessing adaptation of the oldest old age group.

In the final model that included significant correlates from the domain-specific analyses, age, positive affect, and engaged life-style were significantly associated with functional capacity. The analysis suggests that functional ability continues to be strongly associated with age after 100 years of life even when adjusting for individual and social resources. Additional unique variance was only contributed by positive affect and engaged life-style. This underlines the predominant and unique role of positive emotions in relation to functional capacity and the role of past experience with life-style activities. These components appear to be stronger in their relationship to functional capacity than personality, coping or socioeconomic support.

The results of this research have a number of important practical implications. First, service providers and family members need to be prepared for low levels of functional capacity as older adults approach and exceed the 100-year mark. Low levels of functional capacity are particularly noteworthy for centenarians residing in care facilities. Care providers in those settings should encourage very old residents to remain as active as possible. Furthermore, care providers need to be aware that positive affect is related to better functional capacity. Intervention programs could target activities that put centenarians in the best possible mood which then in turn might influence their willingness to engage in activities.

Being sensitive to affective levels is important in providing good social support, and the findings of this study suggest that social support is associated with better functional capacity. Family members and other care providers need to be aware of their crucial role in encouraging the highest possible level of functional capacity. Finally, the association of religious coping and engaged life style with better functional capacity seems to suggest that those working with very 
old adults need to be sensitive to their spiritual needs and to the previous level of activity which centenarians may want to continue to engage in throughout their remaining life.

Our study is not without limitation. The primary limitation of this study concerns the use of proxy information. Some of these proxy assessments may be a more accurate representation of centenarian functioning than others However, as the literature reviewed indicates $(\mathrm{Gu}, 2008$; MacDonald et al., 2009), informant data can be a valid source and may make a contribution to better understand factors influencing functional capacity in very old age. As a number of centenarians are unable to answer questions about themselves, using informant data can be the only sources of reliable information.

Results from centenarian self reports might have provided different outcomes. For example, proxies may react to positive emotions and encourage centenarians to engage in functional activities (such as walking or self care tasks). Similarly, proxy reporters may "interpret" efforts to engage in functional activities as conscientious efforts to master daily tasks. Finally, proxy reporters are usually among the strongest social support providers for centenarians, and it should come as no surprise that proxies would suggest a strong association between social support and higher levels of functioning. Therefore, the findings can only give a few hints to factors related to functional capacity as we have no direct information from the cognitively impaired centenarians.

Other limitations of this study should be considered: Centenarians and their proxies were from a Southeastern state and our results cannot be generalized to all centenarians or centenarians in every region of the United States. Second, only selected variables were used to assess our six hypotheses. Surely, there are other predictive domains and assessments of these 
domains that would be relevant. Third, our design is cross-sectional, and we cannot infer causal relationships from cross-sectional data.

Overall, the results are informative about individual differences in functional capacity. Functional capacity levels continue to be associated with age after 100 years of life, with positive affect levels and with past life-style activities as reported by proxies. They are salient factors of adaptation in very late life. On the whole, the goal is to detect those resources and resilience characteristics that make it possible to not only live a long life but to function at the most optimal level.

\section{References}

Anderson, R. T., James, M. K., Miller, M. E., Worley, A. S., \& Longino, C. F., Jr. (1998). The timing of change: Patterns in transitions in functional status among elderly persons. Journal of Gerontology: Social Sciences, 53B, S17-S27.

Atchley, R. C., \& Scala, M. A. (1998). Long-range antecedents of functional capability in later life. Journal of Aging and Health, 10, 3-19.

Avlund, K., Lund, R., Holstein, B., Due, P., Sakari-Rantola, R., \& Heikkinen, R. L. (2004). The impact of structural and functional characteristics of social relations as determinants of functional decline. Journal of Gerontology: Social Sciences, 59B, S44-S51.

Bradburn, N. M. (1969). The structure of psychological well-being. Chicago: Aldine.

Clark, D. O., Stump, T. E., Miller, D. K., \& Long, J. S. (2007). Educational disparities in the prevalence and consequence of physical vulnerability. Journal of Gerontology: Social Sciences, 62B, S193-S197.

Clarridge, B. R., \& Massagli, M. P. (1989). The use of female spouse proxies in common 
symptom reporting. Medical Care, 27, 352-366.

Costa, P. T., \& McCrae, R.R. (1994). Stability and change in personality from adolescence through adulthood. In C.F. Halverson, G. A. Kohnstamm, \& R. P. Martin (Eds.), The developing structure of temperament and personality from infancy to adulthood. Hillsdale, NJ: Erlbaum.

Cutrona, C. E., \& Russell, D. (1987). The provisions of social relationships and adaptation to stress. In W. H. Jones \& D. Perlman (Eds.), Advances in personal relationships, (Vol. 1, pp. 37-67). Greenwich, CT: JAI Press.

Dohrenwend, B. S., Krasnoff, L., Askenasy, A. R., \& Dohrenwend, B. B. (1978).

Exemplification of a method for scaling life events: the Peri Life Events Scale. Journal of Health and Social Behavior, 19, 205-29.

Duberstein, P. R., Sörensen, S., Lyness, J. M., King, D. A., Conwell, Y., Seidlitz, L., \& Caine, E. D. (2003). Personality is associated with perceived health and functional status in older primary care patients. Psychology and Aging, 18, 25-37.

Elder, G. H., Jr., \& Shanahan. M. J. (2006). The life course and human development. In R. E. Lerner (Ed.), Theoretical models of human development (vol. 1, pp. 665- 715). New York: Wiley.

Feinglass, J., Lin, S., Thomson, J., Sudano, J., Dunlop, D., Song, J., \& Baker, D. W. (2007). Baseline health, socioeconomic status, and 10-year mortality among older middle-aged Americans: Findings from the health and Retirement Study, 1992-2002. Journal of Gerontology: Social Sciences, 62B, S209-S217. 
Felitti, V. J., Anda, R. F., Nordenberg, D., Williamson, D. F., Spitz, A. M., Edwards, V., Koss, M. P., \& Marks, J. S. (1998). The relationship of adult health status to childhood abuse and household dysfunction. American Journal of Preventive Medicine, 14, 245-258.

Femia, E. E., Zarit, S. H., \& Johansson, B. (1997). Predicting change in activities of daily living: A longitudinal study of the oldest old in Sweden. Journal of Gerontology: Psychological Sciences, 52B, P294-P302.

Ferraro, K. F. (2006). Health and aging. In R. H. Binstock, \& L. K. George (Eds.), Handbook of aging and the social sciences, $6^{\text {th }}$ ed. (pp., 238-256). New York: Academic Press.

Fiksenbaum, C. M., Greenglass, E. R., Marques, S. R., \& Eaton, J. (2005). A psychosocial model of functional disability. Ageing International, 30, 278-295.

Fillenbaum, G.G. (1988). Multidimensional functional assessment of older adults: The Duke Older Americans Resources and Services Procedures. Hillsdale: Lawrence Erlbaum Associates.

Folstein, M.F., Folstein, S. E., \& McHugh, P. R. (1975). Mini-mental state: A practical method for grading the cognitive state of patients for the clinician. Journal of Psychiatric Research, 12, 189-198.

Friedman, H. S., Tucker, J. S., Schwartz, J. E., Martin, L. R., Tomlinson-Keasey, C., Wingard, D., L., \& Criqui, M. H. (1995). Childhood conscientiousness and longevity: health behaviors and cause of death. Journal of Personality and Social Psychology, 68, 696-703.

Gondo, Y., \& Hirose, N. (2006). How successful are centenarians? Findings from the Tokyo Centenarian Study. Global Ageing, 4, 34-41.

Gondo, Y. Hirose, N., Arai, U. Y., Inagaki, H., Masui, Y., Yamamura, K., Shimizu, K.-I., Takayama, M., Esihara, Y., Nakazawa, S., \& Kitagawa, K. (2006). Functional status of 
centenarians in Tokyo, Japan: Developing better phenotypes of exceptional longevity. Journal of Gerontology: Medical Sciences, 61A, 305-310.

Gu, D. (2008). General data quality assessment of the CLHLS. In Z. Yi, D. L. Poston, Jr., D. A. Vlosky, \& D. Gu (Eds.), Healthy longevity in China: Demographic, socioeconomic, and psychological dimensions (pp. 39-59). New York: Springer.

Han, K., Burns, G. N., Weed, N. C., Hatchett, G. T., \& Kurokawa, N. K. S. (2009). Evaluation of an observer form of the Coping Inventory for Stressful Situations. Educational and Psychological Measurement, 69, 675-695.

Hobfoll, S. E. (1989). Conservation of resources: A new attempt at conceptualizing stress. American Psychologist, 44, 513-524.

Hogan, D. B., Ebly, E. M., \& Fung, T. S. (1999). Disease, disability, and age in cognitively intact seniors: Results from the Canadian Study of Health and Aging. Journal of Gerontology: Medical Sciences, 54A, M77-82.

Hultsch, D., Hertzog, C., Small, B., \& Dixon, R. (1999). Use it or lose it: engaged lifestyle as a buffer of cognitive decline in aging? Psychology and Aging 14, 245-263.

Idler, E. L., \& Kasl, S. V. (1995). Self-ratings of health: Do they also predict change in functional ability? Journal of Gerontology: Social Sciences, 50B, S344-S353.

Jeune, B., \& Andersen-Ranberg, K. (2000). What can we learn from centenarians? In P. Martin, C. Rott, B. Hagberg, \& K. Morgan (Eds.), Centenarians: Autonomy versus dependence in the oldest old (pp. 9-24). New York: Springer.

Kane, R. L., Kane, R. A., Bershadsky, B., Degenholtz, H., Kling, K., Totten, A., \& Jung, K. (2005). Proxy sources for information on nursing home residents' quality of life. Journal of Gerontology: Social Sciences, 60B, S318-S325. 
Klinkenberg, M., Smit, J. H., Deeg, D. J, Willems, B. L., Onwuteaka-Phipsen, B. D.., \& van der Wal, G. (2003). Proxy reporting in after-death interviews: The use of proxy respondents in retrospective assessment of chronic diseases and symptom burden in the terminal phase of life. Palliative Medicine, 17, 191-201.

Kolanowski, A., Hoffman, L., \& Hofer, S. M. (2007). Concordance of self-report and informant assessment of emotional well-being in nursing home residents with dementia. Journal of Gerontology: Psychological Sciences, 62B, P20-P27.

Krause, N., Shaw, B. A., \& Cairney, J. (2004). A descriptive epidemiology of lifetime trauma and the physical health status of older adults. Psychology and Aging, 19, 637-648.

Krueger, K. R., Wilson, R. S., Shah, R. C., Tang, Y. \& Bennett, D. A. (2006). Personality and incident disability in older persons. Age and Ageing, 35, 428-433.

Liang, J., Shaw, B. A., Krause, N. M., Bennett, J. M., Baum, C., Kobayashi, E., Fukaya, T., Sugihara, Y., \& Sugisawa, H. (2003). Changes in functional states among older adults in Japan: Successful and usual aging. Psychology and Aging, 18, 684-695.

Loewenstein, D. A., Argüelles, S., Bravo, M., Freeman, R. Q., Argüelles, T., Acevedo, A., \& Eisdorfer, C. (2001). Caregivers' judgment of the functional abilities of the Alzheimer's Disease patient: A comparison of proxy reports and objective measures. Journal of Gerontology: Psychological Sciences, 56B, P78-P84.

MacDonald, M., Martin, P., Margrett, J., \& Poon, L. W. (2009). Correspondence of perceptions about centenarians' mental health. Aging and Mental Health, 13, 827-837.

Martin, P. (2007). Personality and coping among centenarians. In L. W. Poon \& T. T. Perls (Eds.), Annual Review of Gerontology and Geriatrics, vol. 27: Biopsychosocial approaches to longevity (pp. 89-106). New York: Springer. 
Martin, P., \& Martin, M. (2002). Proximal and distal influences on development: The model of developmental adaptation. Developmental Review, 22, 78-96.

Martin, P., Rott, C., Poon, L. W., Courtenay, B., \& Lehr, U. M. (2001). A molecular view of coping behavior in older adults. Journal of Aging and Health, 13, 72-91.

Mendes de Leon, C. F., Barnes, L. L., Bienias, J. L., Skarupski, K. A., \& Evans, D. A. (2005). Racial disparities in disability: Recent evidence from self-reported and performancebased disability measures in a population-based study of older adults. Journal of Gerontology: Social Sciences, 60B, S263-S271.

Mosley, R. R. II., \& Wolinsky, F. F. (1986).The use of proxies in health surveys: Substantive and policy implications. Medical Care, 24, 496-510.

Neumann, P. J., Araki, S. S., \& Gutterman, E. M. (2000). The use of proxy respondents in studies of older adults: Lessons, challenges, and opportunities. Journal of the American Geriatrics Society, 48, 1646-1654.

Parmelee, P. A., Lawton, M. P., \& Katz, I. R. (1998). The structure of depression among elderly institution residents. Affective and somatic correlates of physical frailty. Journal of Gerontology: Medical Sciences, 53A, M155-162.

Poon, L. W., Clayton, G. M., Martin, P., Johnson, M. A., Courtenay, B. C., Sweaney, A. L., Merriam, S. B., Pless, B. S., \& Thielman, S. B. (1992). The Georgia Centenarian Study. International Journal of Aging and Human Development, 34, 1-17.

Poon, L. W., Jazwinski, S.M., Green, R. C., Woodard, J. L., Martin, P., Rodgers, W. L., Johnson, M. A., Hausman, D., Arnold, J., Davey, A., Batzer, M. A., Markesbery, W. R., Gearing, M., Siegler, I. C., Reynolds, S., \& Dai, J. (2007). Methodological considerations in studying centenarians: Lessons learned from the Georgia Centenarian Studies. In L. W. 
Poon \& T. T. Perls (Eds.), Annual Review of Gerontology and Geriatrics: Vol. 27. Biopsychosocial approaches to longevity (pp. 231-264). New York: Springer.

Poon, L. W., Johnson, M. A., Davey, A., Dawson, D. V., Siegler, I. C., \& Martin, P. (2000). Psycho-social predictors of survival among centenarians. In P. Martin, Ch. Rott, B. Hagberg, \& K. Morgan (Eds.), Centenarians: Autonomy versus dependence in the oldest old (pp. 77-89). New York: Springer.

Rodgers, W. L., \& Herzog, A. R. (1992). Collecting data about the oldest: Problems and procedures. In R. M. Suzman, D. P. Willis, \& K. G. Manton (Eds.), The oldest old (pp. 135-156). New York: Oxford University Press.

Rothman, M. L., Hedrick, K. A., Bulcroft, K. A., Kickam, D. H., \& Rubenstein, L.Z. (1991). The validity of proxy-generated scores as measures of patient health status. Medical Care, 29, $115-124$.

Ryff, C. D., Singer, B., Love, G. D., \& Essex, M. J. (1998). Resilience in adulthood and later life: Defining features and dynamic processes. In J. Lomranz (Ed.), Handbook of aging and mental health: An integrative approach (pp. 69-99). New York: Plenum.

Samuelsson, S.-M., Bauer Alfredson, B., Hagberg, B., Samuelsson, G., Nordbeck, B., Brun, A., Gustafson, L., \& Risberg, J. (1997). The Swedish Centenarian study: A multidisciplinary study of five consecutive cohorts at the age of 100. International Journal of Aging and Human Development, 45, 223-253.

Schafer, J. L., \& Graham, J. W. (2002). Missing data: Our view of the state of the art. Psychological Methods, 7, 147-177. doi: 10.1037//1082-989X.7.2.147

Schatzberg, K.L., Sudha, S., \& Mutran, E.J. (1998). Elder-proxy agreement concerning the functional status and medical history of the older person: The impact of caregiver burden 
and depressive symptomatology. Journal of the American Geriatrics Society, 46, 1103 1111.

Schneider, L., \& Schimmack, U. (2009). Self-informant agreement in well-being ratings: A meta-analysis. Social Indicators Research, 94, 363-376.

Selim, A. J., Fincke, G., Berlowitz, D. R., Miller, D. R., Qian, S. X., Lee, A., Cong, Z., Rogers, W., Selim, B. J., Ren, X. S., Spiro, A III., \& Kazis, L. E. (2005). Comprehensive health status assessment of centenarians: Results from the 1999 Large Health Survey of Veteran Enrollees. Journal of Gerontology: Medical Sciences, 60A, 515-519.

Steinbach, U. (1992). Social networks, institutionalization, and mortality among elderly people in the United States. Journal of Gerontology: Social Sciences, 47, S183-190.

Takayama, M., Hirose, N., Arai, Y., Gondo, Y., Shimizu, K., Ebihara, Y., Yamamura, K., Nakazawa, S., Inagaki, M., Masui, Y., \& Kitagawa, K. (2007). Morbidity of Tokyo-area centenarians and its relationship to functional status. Journal of Gerontology: Medical Sciences, 62A, 774-782.

Tang, S. T., \& McCorkle, R. (2002). Use of family proxies in quality of life research for cancer patients at the end of life: A literature review. Cancer Investigation, 20, 1086-1104.

Todorov, A., \& Kirchner, C. (2000). Bias in proxies' reports of disability: data from the National Health Interview Survey on disability. American Journal of Public Health, 90, 12481253.

Walsh, E. G., Wu, B., Mitchell, J. B., \& Berkmann, L. F. (2003). Cognitive function and acute care utilization. Journal of Gerontology: Social Sciences, 58B, S38-S49. 
Watkins, R. A., Guariglia, R., Kaye, J. A., \& Janowsky, J. S. (2001). Informants' knowledge of reproductive history and estrogen replacement. Journal of Gerontology: Medical Sciences, 56A, M176-M179. 
Table 1

Demographic Variables

Functional Capacity

Variables

$N \quad$ Percent $\quad M \quad S D$

$M \quad S D$

Age

234

$100.2 \quad 2.02$

Gender

$\begin{array}{lrrrr}\text { Male } & 41 & 17.5 & 16.6 & 6.72 \\ \text { Female } & 193 & 82.5 & 14.4 & 7.61 \\ \text { Total } & 234 & 100.0 & & \end{array}$

Residence

\begin{tabular}{lrrrr} 
Community & 103 & 44.2 & 17.8 & 6.77 \\
Personal Care & \multicolumn{1}{c}{47} & 20.2 & 17.5 & 6.82 \\
Skilled Nursing & 83 & 35.6 & 9.2 & 5.34 \\
Total & 233 & 100.0 & &
\end{tabular}

Education

$\begin{array}{lcccc}\text { 0-4 Years } & 11 & 4.9 & 12.1 & 7.74 \\ \text { 5-8 Years } & 53 & 23.8 & 14.1 & 6.90 \\ \text { High School, Incomplete } & 26 & 11.7 & 13.7 & 7.75 \\ \text { High School, Complete } & 43 & 19.3 & 13.9 & 8.09 \\ \text { Business/Trade School } & 28 & 12.6 & 14.8 & 3.37 \\ & & & \text { (table 1 continued) }\end{array}$


Table 1 continued

\begin{tabular}{|c|c|c|c|c|c|c|}
\hline \multirow[b]{2}{*}{ Variables } & \multirow[b]{2}{*}{$N$} & \multirow[b]{2}{*}{ Percent } & \multirow[b]{2}{*}{$M$} & \multirow[b]{2}{*}{$S D$} & \multicolumn{2}{|c|}{ Functional Capacity } \\
\hline & & & & & $M$ & $S D$ \\
\hline College, 1-3 Years & 22 & 9.9 & & & 16.4 & 6.38 \\
\hline College, 4 Years & 19 & 9.4 & & & 16.5 & 8.03 \\
\hline Postgraduate & 21 & 9.4 & & & 19.6 & 5.11 \\
\hline Total & 223 & $100.0^{\mathrm{a}}$ & & & & \\
\hline \multicolumn{7}{|l|}{ Occupation } \\
\hline Professional & 62 & 30.2 & & & 15.8 & 7.29 \\
\hline Manager & 30 & 14.6 & & & 15.2 & 8.28 \\
\hline Farmer, $50+$ Acres & 17 & 8.3 & & & 11.6 & 7.15 \\
\hline Clerical, Sales, Technical & 31 & 15.1 & & & 16.0 & 7.24 \\
\hline Skilled & 12 & 5.9 & & & 13.7 & 7.58 \\
\hline Semi-Skilled & 17 & 8.3 & & & 15.3 & 7.65 \\
\hline Service Worker & 18 & 8.8 & & & 15.6 & 7.03 \\
\hline Unskilled & 16 & 7.8 & & & 11.9 & 7.16 \\
\hline Farm Laborer & 2 & 1.0 & & & 10.5 & 0.71 \\
\hline Total & 205 & 100.0 & & & & \\
\hline
\end{tabular}

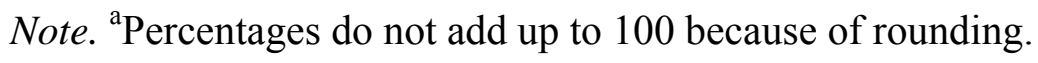


Table 2

Descriptive Data

\begin{tabular}{|c|c|c|c|c|}
\hline Variables & $N$ & Range & $M$ & $S D$ \\
\hline \multicolumn{5}{|l|}{ Health Variables } \\
\hline General Health & 233 & $0-3$ & 1.97 & 0.79 \\
\hline Functional Capacity & 209 & $0-28$ & 14.71 & 7.50 \\
\hline \multicolumn{5}{|l|}{ Individual Resources } \\
\hline Neuroticism & 228 & $61-190$ & 119.76 & 22.10 \\
\hline Extraversion & 228 & $92-199$ & 152.00 & 19.53 \\
\hline Openness to Ideas & 228 & $77-183$ & 138.21 & 16.32 \\
\hline Agreeableness & 228 & $95-217$ & 170.96 & 23.10 \\
\hline Conscientiousness & 228 & $100-218$ & 172.13 & 21.88 \\
\hline \multicolumn{5}{|l|}{ Social Resources } \\
\hline Social Provisions & 210 & $22-47$ & 37.62 & 4.81 \\
\hline Perceived Economic Status & 223 & $0-4$ & 2.67 & 1.49 \\
\hline \multicolumn{5}{|l|}{ Affect } \\
\hline Negative Affect & 214 & $5-19$ & 8.09 & 3.71 \\
\hline Positive Affect & 207 & $5-20$ & 11.71 & 4.11 \\
\hline \multicolumn{5}{|l|}{ Coping } \\
\hline Religious Coping & 208 & $0-4$ & 3.07 & 1.17 \\
\hline
\end{tabular}


Table 2 continued

\begin{tabular}{|c|c|c|c|c|}
\hline Variables & $N$ & Range & $M$ & $S D$ \\
\hline \multicolumn{5}{|l|}{ Lifestyle } \\
\hline Engaged Lifestyle & 188 & $0-8$ & 4.05 & 1.91 \\
\hline \multicolumn{5}{|c|}{ Events and Experiences } \\
\hline Proximal Events & 224 & $0-5$ & 0.65 & 1.00 \\
\hline Distal Events & 224 & $0-12$ & 4.14 & 3.09 \\
\hline Education & 223 & $1-8$ & 4.22 & 2.07 \\
\hline Occupation & 205 & $1-9$ & 3.57 & 2.43 \\
\hline
\end{tabular}


Table 3

Predictors of Functional Capacity (Domain-Specific Models)

\begin{tabular}{|c|c|c|c|c|c|}
\hline Variable & $\mathrm{b}$ & $\mathrm{SE}(\mathrm{b})$ & $\beta^{\mathrm{a}}$ & $\begin{array}{l}\text { Adjusted } \\
\mathrm{R}^{2}\end{array}$ & $\begin{array}{l}\mathrm{R}^{2} \\
\text { Change }\end{array}$ \\
\hline Demographic Model & & $n=209$ & & & \\
\hline Age & -1.22 & 0.20 & $-0.33 * * *$ & .51 & \\
\hline Gender & -0.84 & 0.98 & -0.04 & & \\
\hline Residence & -2.78 & 0.44 & $-0.33 * * *$ & & \\
\hline Ethnicity & -0.85 & 0.87 & -0.05 & & \\
\hline General Health & 3.97 & 0.47 & $0.42 * * *$ & & \\
\hline Affect Model & & $=185$ & & .30 & $.12 * * *$ \\
\hline Negative Affect & -0.16 & 0.13 & -0.08 & & \\
\hline Positive Affect & 0.59 & 0.12 & $0.32 * * *$ & & \\
\hline Personality Model & & $n=204$ & & .24 & $.06^{* *}$ \\
\hline Neuroticism & -0.03 & 0.03 & -0.09 & & \\
\hline Extraversion & 0.01 & 0.03 & 0.02 & & \\
\hline Openness & 0.02 & 0.03 & 0.05 & & \\
\hline Agreeableness & -0.02 & 0.03 & -0.05 & & \\
\hline Conscientiousness & 0.06 & 0.03 & $0.17 *$ & & \\
\hline
\end{tabular}

(table continues) 
Table 3 continued

\begin{tabular}{|c|c|c|c|c|c|c|}
\hline Variable & $\mathrm{b}$ & $\mathrm{SE}(\mathrm{b})$ & $\beta$ & $\begin{array}{l}\text { Adjusted } \\
\mathrm{R}^{2}\end{array}$ & $\begin{array}{l}\mathrm{R}^{2} \\
\text { Change }\end{array}$ & \\
\hline Social and Economic Model & & $n=188$ & & .25 & $.07 * * *$ & \\
\hline Social Provisions & 0.29 & 0.10 & $0.18 * *$ & & & \\
\hline Perceived Economic Status & 0.87 & 0.34 & $0.17 *$ & & & \\
\hline Life Events and Coping Model & & $n=186$ & & .36 & $.03 *$ & \\
\hline Proximal Events & 0.17 & 0.51 & 0.02 & & & \\
\hline Religious Coping & 1.30 & 0.42 & $0.20 * *$ & & & \\
\hline Distal Experience Model & & & $n=169$ & & .23 & $.06^{*}$ \\
\hline Engaged Lifestyle & 0.94 & 0.37 & $0.24 *$ & & & \\
\hline Distal Events & 0.02 & 0.17 & 0.01 & & & \\
\hline Education & 0.17 & 0.38 & 0.05 & & & \\
\hline Occupation & 0.15 & 0.28 & 0.05 & & & \\
\hline
\end{tabular}

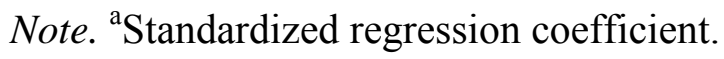

${ }^{*} p<.05 .{ }^{* *} p<.01 .{ }^{* * *} p<.001$. 
Table 4

Final Model

Variable

b $\quad \mathrm{SE}(\mathrm{b})$

$\beta^{\mathrm{a}}$

Adjusted $\mathrm{R}^{2}$

$\mathrm{R}^{2} \quad$ Change

$n=169$

.33

$.16^{* * *}$

Age

$\begin{array}{lll}-1.37 & 0.25 & -0.37 * * *\end{array}$

Ethnicity

$\begin{array}{lll}0.79 & 1.21 & 0.05\end{array}$

Gender

$\begin{array}{lll}0.15 & 1.30 \quad 0.01\end{array}$

Positive Affect

0.46

0.14

$0.25^{* * *}$

Conscientiousness

$\begin{array}{lll}0.01 & 0.03 & 0.03\end{array}$

Social Provisions

$\begin{array}{lll}0.03 & 0.12 & 0.02\end{array}$

Perceived Economic Status

$\begin{array}{lll}0.55 & 0.35 & 0.11\end{array}$

Religious Coping

$\begin{array}{lll}0.40 & 0.46 \quad 0.06\end{array}$

Engaged Life-Style

$0.61 \quad 0.29 \quad 0.16^{*}$

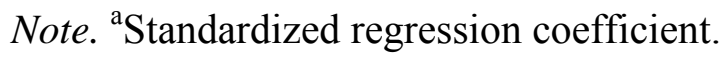

${ }^{*} p<.05 .{ }^{* *} p<.01 .{ }^{* * *} p<.001$. 